$\begin{array}{ll}\text { Research Square } & \text { Preprints are preliminary reports that have not undergone peer review. } \\ \text { They should not be considered conclusive, used to inform clinical practice, } \\ \text { or referenced by the media as validated information. }\end{array}$

\title{
Effectiveness of a transdiagnostic universal prevention program on anxiety in junior high school students after school closure due to the COVID-19 pandemic
}

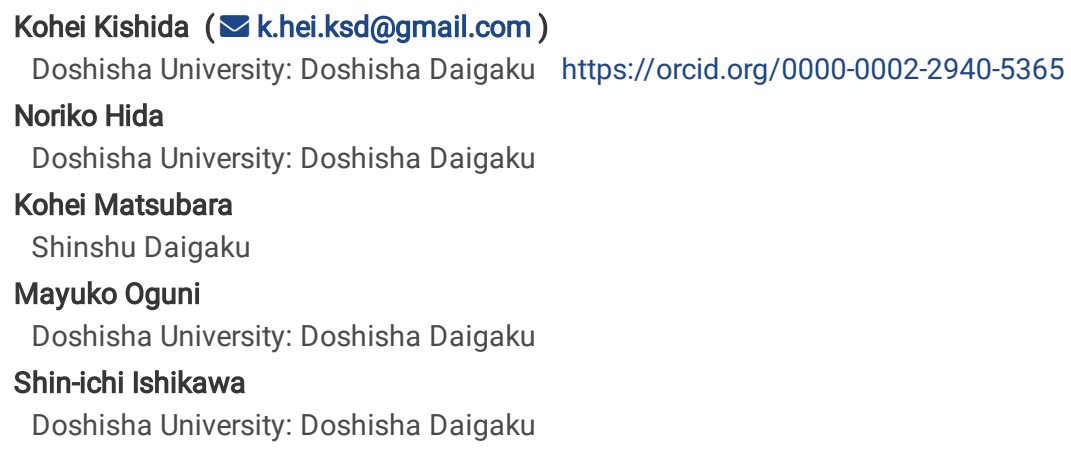

\section{Research Article}

Keywords: universal prevention, school closure, anxiety, adolescents

Posted Date: January 25th, 2022

DOI: https://doi.org/10.21203/rs.3.rs-1264505/v1

License: () (i) This work is licensed under a Creative Commons Attribution 4.0 International License. Read Full License 


\section{Abstract}

School closures due to the coronavirus disease 2019 (COVID-19) pandemic have worsened mental health problems for children and adolescents worldwide. We aimed to examine the effectiveness of a transdiagnostic universal prevention program for the mental health of junior high school students after a nationwide school closure during the COVID-19 outbreak in Japan. A total of 117 junior high school students were included in the analysis. We used the Unified Universal Prevention Program for Diverse Disorders (Up2-D2) program; the Up2-D2 comprises cognitive-behavioral and positive psychological interventions provided over twelve 45-minute sessions. The program was originally implemented between June and July 2020 , immediately after pandemic-related school closures had ended in Japan. The program assessments were based on students' responses to a questionnaire incorporating five scales to measure indicators of internalizing and externalizing problems. Assessments were carried out before, immediately after, two-month, and six-month after implementing the program using student-reported questionnaires. Mixed models for the whole sample showed small anxiety improvement effects immediately post-intervention and two-month, and six-month assessments $(g=-0.25, g=-0.44$, and $g=-0.30$, respectively). The anxiety reducing effects were even greater for the higher-anxiety group at the post-, 2-month, and 6-month assessments $(g=$ $-1.48 ; g=-1.59 ; g=-1.06$, respectively). These results indicate that the transdiagnostic universal prevention intervention effectively reduced anxiety for junior high students returning to school following school closures related to the COVID-19 pandemic in Japan.

\section{Introduction}

The coronavirus disease 2019 (COVID-19) pandemic has caused mental health problems in children and adolescents worldwide (Berger, Jamshidi, Reupert, Jobson, \& Miko, 2021; Panda et al., 2021; Samji et al., 2021). Many containment policies and quarantine measures, such as lockdown, school closures, and self-isolation, have been implemented worldwide to prevent the spread of COVID-19. A meta-analysis of the psychological and behavioral impacts of COVID-19 pandemic lockdown and quarantine measures on 22,996 children/adolescents revealed that $34.5 \%, 41.7 \%$, $42.3 \%$, and $30.8 \%$ of children were suffering from anxiety, depression, irritability, and inattention, respectively (Panda et al., 2021). Additionally, at least 22.5\% of children have a significant fear of COVID-19 (Panda et al., 2021). Worsening children's mental health during this pandemic is evident, and appropriate preventions and treatments are needed.

In April 2020, 81.1\% of schools worldwide were fully or partially closed owing to the COVID-19 pandemic (UNESCO, 2021). In Japan, the government requested the first nationwide school closure on March 2, 2020; 98\% of schools in Japan were closed by March 16 (MEXT, 2020). Several studies have explored the impact of school closures on mental health problems among Japanese children and adolescents during the pandemic (Isumi, Doi, Yamaoka, Takahashi, \& Fujiwara, 2020; Kishida, Tsuda, Waite, Creswell, \& Ishikawa, 2021; Takahashi \& Honda, 2021). One revealed a relationship between local school closures and mental health problems in 1,984 Japanese children and adolescents aged 6-15 years (Kishida, Tsuda et al., 2021); they found higher student scores in both internalizing problems (anxiety and depression) and externalizing problems (conduct problems and oppositionality) associated with school closures compared to when schools were fully open, and anxiety was affected most (Kishida, Tsuda, et al., 2021). Therefore, appropriate and effective preventive interventions are required.

Preventive interventions in schools can be effective and useful for delivering psychological support to a large number of children and adolescents. Preventive interventions are categorized into indicative, selective, and universal (Mrazek \& Haggerty, 1994). Universal prevention, an approach designed for an entire population, eliminates unnecessary screening to detect high-risk children and adolescents, minimizes stigma from the screening procedure, and allows for the inclusion of children and adolescents who may develop mental health problems in the future (Horowitz \& Garber, 2006; WernerSeidler, Perry, Calear, Newby, \& Christensen, 2017). Furthermore, several systematic reviews and meta-analyses have indicated that universal preventive interventions are effective in addressing internalizing and externalizing problems in children and adolescents (Dray et al., 2017; Hendriks, Bartels, Colins, \& Finkenauer, 2018; Sanchez Cornacchio, Poznanski, Golik, Chou, \& Comer, 2018; Werner-Seidler et al., 2017). The current situation, wherein most children and adolescents are negatively affected by the pandemic-related school closures, calls for the implementation of such interventions.

The Universal Unified Prevention Program for Diverse Disorders (Up2-D2; Ishikawa et al., 2019; Hida, Ishikawa, Murasawa, \& Oguni, 2020; Kishida, Hida, \& Ishikawa, 2021; Oka et al., 2021) is a newly developed school-based transdiagnostic universal preventive intervention program that addresses both internalizing and externalizing problems in children and adolescents. The Up2-D2 consists of 12 sessions based on cognitive-behavioral and positive psychological interventions, and was designed to be implemented by teachers. Before the COVID-19 pandemic began, Oka et al. (2021) conducted a feasibility study from September 2016 to March 2017 using the Up2-D2. The 396 children who participated in the Up2-D2 exhibited increased selfefficacy and social skills and decreased general difficulties after receiving the program. After the pandemic began and the first nationwide school closure ended in Japan, the program was implemented for 120 junior high school students (Hida, et al., 2020) and results showed an improvement in anxiety after the program. However, this study only reported the program results immediately after its implementation. Therefore, follow-up assessments are necessary to detect the effectiveness of the program because the COVID-19 pandemic has been spreading in waves, and mental health problems may deteriorate accordingly.

This study aimed to examine the follow-up effectiveness of the Up2-D2 (Ishikawa et al., 2019) for mental health problems among junior high school students after the nationwide school closure due to the COVID-19 pandemic in Japan. We used the original data from the pre- and post-assessments of a previous study (Hida et al., 2020) and then performed two- and six-month follow-up assessments. We hypothesized that the anxiety improved by the implementation of the Up2-D2 post-assessment would be maintained at the two- and six-month follow-ups. Moreover, we hypothesized that other mental health problems would not worsen at the two- and six-month follow-ups. 


\section{Methods}

\section{Participants and recruitment}

The participants were 120 junior high school students from three classes at a public junior high school. The school's principal, who had participated in a training workshop for the program in 2019, had requested that our research team implement the program in the principal's school before the spread of COVID-19 started in Japan. However, during the first wave of the COVID-19 pandemic, the school was closed in accordance with the government's request and reopened on May 7, 2020. The program was implemented in schools in June and July 2020. After the nationwide school closure, no closures were implemented in the participating school during the second (August 2020) and third waves (January 2021) of the pandemic in Japan. The study was conducted with the approval of the Institutional Review Board of the authors' university (approval no. 201904). Written informed consent was obtained from school principals. Additionally, oral informed consent was obtained from all the students.

\section{Intervention}

The Up2-D2 (Ishikawa et al., 2019), a school-based universal prevention program for internalizing and externalizing problems in children, comprises 12 sessions based on cognitive-behavioral and positive psychological interventions: psychoeducation about emotion (session 1), behavioral activation (session 2), social skills training (sessions 3 and 4), relaxation (session 5), strength work (session 6), cognitive restructuring (sessions 7 and 8 ), exposure (sessions 9 and 10), problem-solving (session 11), and review and conclusion (session 12). Each session lasted 45 minutes and was conducted using the following procedures: a) introduction (i.e., reviewing the last session and explaining the goal and purpose of the session); b) learning target skills (i.e., cognitive-behavioral or positive psychological skills); c) practicing target skills (in both individual and group activities); and d) conclusion (i.e., explaining the homework and summarizing the session). Worksheets were distributed in each session to assist the children in learning the program components. Furthermore, to run the program in their classes, teachers were provided with teaching plans that included specific program procedures in school settings. Although the program was originally designed for elementary school students (grades 4-6), we conducted this study with junior high school students (grade 7).

\section{Program Implementation (Training, supervision and follow-up procedure)}

The participating teachers received two hours of teacher training before implementing the program, which included an overview of the program, the flow of each session, and how to run the program in class. During the implementation, the second author, who had also provided the teacher training, provided three rounds of one-hour supervision. The supervisor discussed the contents and intervention rationales of each session with the teachers and answered their questions about implementing the program in their classes. Finally, to improve the lasting effectiveness of the program, we distributed a handout describing the skills acquired in the program, which included specific examples of how the learned skills can be used in daily life. The teachers had the students use their skills in their classes, schools, and homes based on this information.

\section{Measures}

Assessments were carried out before, immediately after, two months, and six months after implementing the program using student-reported questionnaires. The questionnaires comprised the items of the five scales described below.

Strengths and Difficulties Questionnaire (SDQ)

The Japanese version of the SDQ is a self-report questionnaire that measures children's emotional/behavioral difficulties and positive attitudes (Goodman, 2001; Noda, Ito, \& Harada, 2013). It has five subscales: emotional symptoms, conduct problems, hyperactivity/inattention, peer relationship problems, and prosocial behavior. The total score indicates general difficulties for all subscales except prosocial behavior. The internal consistencies of the general difficulties of the SDQ-P for the whole sample were $0.77,0.73,0.77$, and 0.70 at the pre-, post, two-month, and six-month assessments, respectively.

General Self-Efficacy Scale for Children-Revised (GSESC-R)

The GSESC-R is a self-report questionnaire for general self-efficacy in children (Fukui et al., 2009) with two subscales: sensitivity to failure and a positive attitude. The total GSESC-R score was used to assess general self-efficacy. Higher scores indicate higher self-efficacy. The internal consistencies of the total score of the GSESC-R for the whole sample were $0.86,0.89,0.90$, and 0.88 at the pre, post, two-month, and six-month assessments, respectively.

Short version of the Spence Children's Anxiety Scale (Short CAS)

The Short CAS is a self-report questionnaire that assesses anxiety symptoms in children and adolescents (Spence et al., 2014). The validity and reliability of the Japanese version of the Short CAS have been confirmed (Ishikawa et al., 2018). Higher scores indicated higher anxiety symptoms. The internal consistencies of the Short CAS for the whole sample were $0.87,0.86,0.88$, and 0.90 at pre, post, two-month, and six-month assessments, respectively.

Depression Self-Rating Scale for Children (DSRS-C) 
The DSRS-C (Birleson, 1981) is a self-report questionnaire that assesses depressive symptoms in children and adolescents. The reliability and validity of the Japanese version of the DSRS-C have been confirmed (Denda, Kako, Kitagawa, \& Koyama, 2006). A short version of the DSRS-C developed by Namikawa et al. (2011) was used in this study. Higher scores indicated higher levels of depression. The internal consistencies of the DSRS-C for the whole sample were $0.77,0.79,0.82$, and 0.79 at pre, post, two-month, and six-month assessments, respectively.

Anger Scale for Children and Adolescents (ASCA)

The ASCA is a self-report questionnaire for anger in children and adolescents (Takebe, Kishida, Sato, Takahash, \& Sato, 2017). The reliability and validity of the ASCA have been examined (Takebe et al., 2017). Higher scores indicated higher levels of anger. The internal consistencies of the ASCA for the whole sample were $0.93,0.95,0.94$, and 0.96 at the pre, post, two-month, and six-month assessments, respectively.

\section{Statistical analysis}

Analyses were conducted for all participant samples and separately for those with high anxiety. This study used mixed models of individuals and classes as variable effects, and time points (pre-assessment, post-assessment, two-month follow-up, and six-month follow-up) as fixed effects. We used the Bonferroni method for post hoc tests and Hedges' g for effect sizes of $0.20,0.50$, and 0.80 , which are considered small, medium, and large, respectively.

\section{Results}

Overall, 117 students (45 boys, 72 girls; mean age $12.28 \pm 0.45$ years) were included for analyses in this study; three students who did not respond to the pre-assessment questionnaire were previously excluded. The total sample included 20 students ( 4 males and 16 females; mean age $12.40 \pm 0.50$ years) who scored more than the mean +1 SD (14 points) on the Short CAS at pre-assessment, indicating relatively high anxiety levels.

The results of mixed models for the whole samples showed significant results for anxiety $(F=10.08, p<.05)$ and sensitivity of failure experience $(F=$ $5.37, p<.05)$. Post hoc tests for anxiety showed significant improvements at post-assessment, two-month follow-up, and six-month follow-up compared to pre-assessment (all $p<.05$ ). For sensitivity of failure experience, significant improvements at post-assessment and two-month follow-up compared to pre-assessment (all $p<.05$ ). Besides, anxiety decreased with small effects at post-assessment, two-month follow-up, and six-month follow-up ( $g=-0.25 ; g=-0.44 ; g=-0.30$, respectively). Furthermore, sensitivity of failure experience increased with small effects at post-assessment and two-month follow-up ( $g=0.20 ; g=0.22$, respectively). The results for the whole sample are shown in Table 1 and Table 2.

Table 1

Mean scores and results of the mixed model for the total sample (Total sample $N=117$ )

\begin{tabular}{|c|c|c|c|c|c|c|c|c|c|c|c|c|c|c|}
\hline & \multicolumn{3}{|c|}{ Pre-assessment } & \multicolumn{3}{|c|}{ Post-assessment } & \multicolumn{3}{|c|}{ 2-month FU } & \multicolumn{3}{|c|}{ 6-month FU } & \multicolumn{2}{|l|}{$F$} \\
\hline & $M$ & $S D$ & $n$ & $M$ & $S D$ & $n$ & $M$ & $S D$ & $n$ & $M$ & $S D$ & $n$ & & \\
\hline SDQ (Total difficulties) & 9.97 & 4.56 & 113 & 10.18 & 4.08 & 106 & 10.27 & 4.50 & 103 & 9.92 & 3.85 & 106 & 0.68 & \\
\hline Emotional symptoms & 2.79 & 2.57 & 117 & 2.60 & 2.48 & 112 & 2.50 & 2.57 & 108 & 2.40 & 2.31 & 109 & 1.37 & \\
\hline Conduct problems & 1.69 & 1.27 & 116 & 1.72 & 1.36 & 107 & 1.81 & 1.41 & 106 & 1.51 & 1.03 & 108 & 2.27 & \\
\hline Hyperactivity/inattention & 3.51 & 2.27 & 116 & 3.60 & 2.30 & 111 & 3.53 & 2.30 & 107 & 3.76 & 2.03 & 109 & 1.63 & \\
\hline $\begin{array}{l}\text { Peer relationship } \\
\text { problems }\end{array}$ & 2.00 & 1.26 & 115 & 2.21 & 1.47 & 112 & 2.31 & 1.49 & 106 & 2.12 & 1.47 & 107 & 2.10 & \\
\hline Prosocial behavior & 5.29 & 2.20 & 116 & 5.28 & 2.19 & 110 & 5.44 & 2.39 & 107 & 5.64 & 2.30 & 108 & 1.65 & \\
\hline Self-Efficacy & 47.25 & 9.16 & 116 & 48.38 & 10.30 & 108 & 48.22 & 10.61 & 104 & 47.05 & 10.04 & 107 & 2.61 & \\
\hline $\begin{array}{l}\text { Sensitivity of failure } \\
\text { experience }\end{array}$ & 23.68 & 4.67 & 117 & 24.83 & 6.77 & 109 & 25.03 & 7.40 & 107 & 23.90 & 6.88 & 109 & 5.37 & * \\
\hline Positive attitude & 23.50 & 6.40 & 116 & 23.58 & 5.21 & 111 & 23.33 & 5.09 & 105 & 23.13 & 4.93 & 107 & 1.48 & \\
\hline Anxiety & 8.31 & 5.45 & 116 & 6.96 & 5.18 & 111 & 5.96 & 5.27 & 106 & 6.68 & 5.51 & 109 & 10.08 & ** \\
\hline Depression & 5.00 & 3.11 & 114 & 4.91 & 3.28 & 109 & 4.82 & 3.52 & 106 & 4.78 & 3.26 & 105 & 0.28 & \\
\hline Anger & 2.19 & 3.77 & 117 & 2.93 & 4.38 & 112 & 2.29 & 3.91 & 108 & 2.90 & 4.65 & 107 & 3.18 & \\
\hline
\end{tabular}


Table 2

Intervention effect sizes for the total sample compared to pre-intervention assessments $(N=117)$

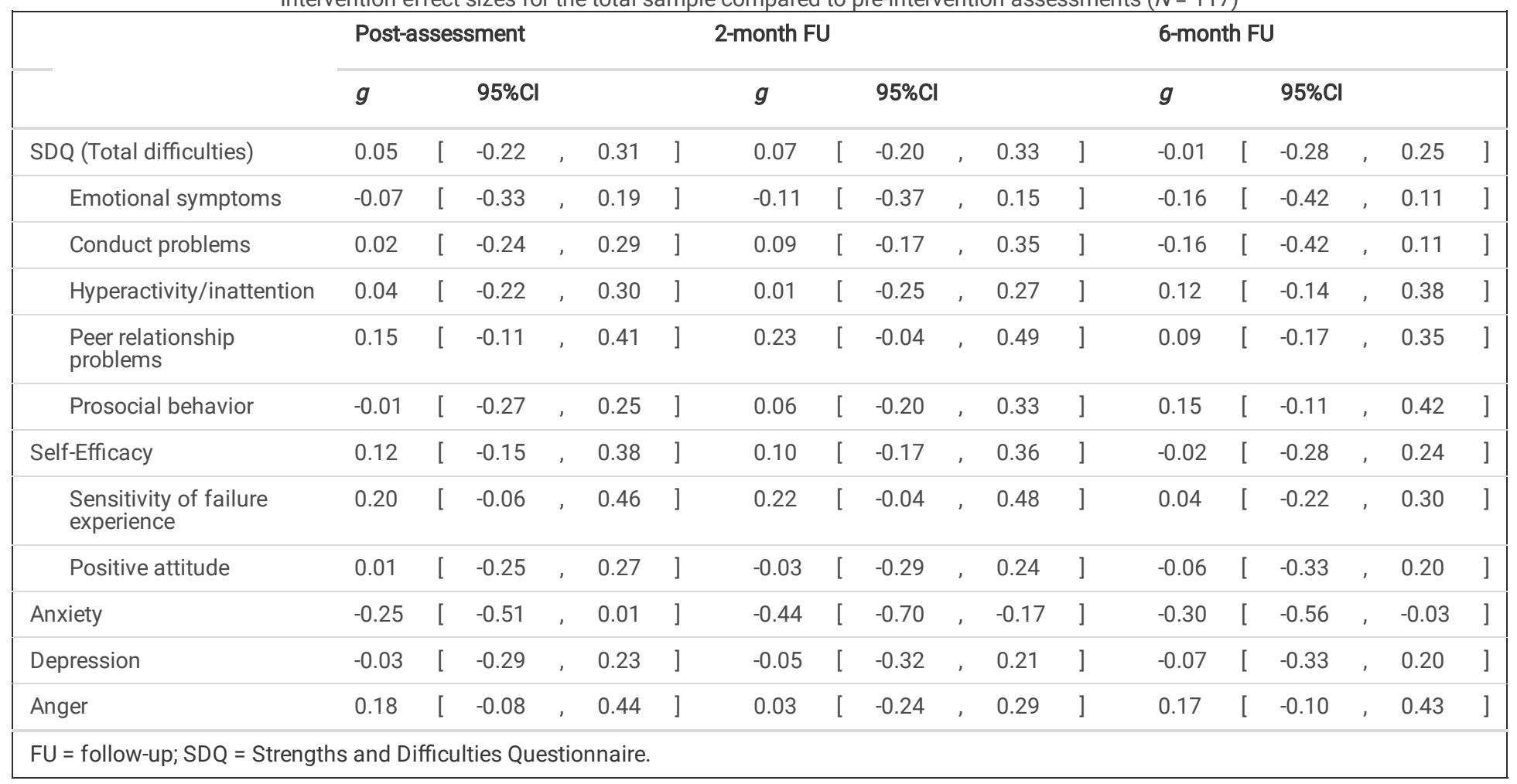

The mixed models for the students with higher anxiety showed significant results for general difficulties $(F=6.32, p<.05)$, emotional symptoms $(F=$ $3.46, p<.05)$, and anxiety $(F=11.59, p<.05)$. Compared to pre-assessment, post hoc tests showed significant improvements (all $p<.05)$ for: general difficulties at post-assessment and six-month follow-up; emotional symptoms at six-month follow-up; anxiety at post-assessment, two-month follow-up, and six-month follow-up. Besides, anxiety decreased with large effects at post-assessment, two-month follow-up, and six-month follow-up ( $g=-1.48 ; g$ $=-1.59 ; g=-1.06$, respectively). General difficulties, emotional symptoms, conduct problems, and depression decreased with moderate effects at sixmonth follow-up $(d=-0.61 ; d=-0.49 ; d=-0.50 ; d=-0.64$, respectively). The results for the students with higher anxiety are shown in Table 3 and Table 4 .

Table 3

Mean scores and results of the mixed model for the samples with higher anxiety symptoms $(N=20)$

\begin{tabular}{|c|c|c|c|c|c|c|c|c|c|c|c|c|c|c|}
\hline & \multicolumn{3}{|c|}{ Pre-assessment } & \multicolumn{3}{|c|}{ Post-assessment } & \multicolumn{3}{|c|}{ 2-month FU } & \multicolumn{3}{|c|}{ 6-month FU } & \multicolumn{2}{|l|}{$F$} \\
\hline & $M$ & $S D$ & $n$ & $M$ & $S D$ & $n$ & $M$ & $S D$ & $n$ & $M$ & $S D$ & $n$ & & \\
\hline SDQ (Total difficulties) & 15.06 & 6.24 & 18 & 13.06 & 4.63 & 17 & 14.18 & 4.38 & 17 & 11.78 & 4.07 & 18 & 6.32 & * \\
\hline Emotional symptoms & 5.60 & 2.62 & 20 & 4.67 & 3.20 & 18 & 5.47 & 2.85 & 17 & 4.22 & 2.86 & 18 & 3.46 & $\star \star$ \\
\hline Conduct problems & 2.42 & 2.01 & 19 & 2.24 & 1.64 & 17 & 2.18 & 1.55 & 17 & 1.61 & 0.92 & 18 & 1.70 & \\
\hline Hyperactivity/inattention & 3.95 & 2.19 & 20 & 3.17 & 1.92 & 18 & 3.76 & 2.17 & 17 & 3.44 & 2.18 & 18 & 1.52 & \\
\hline Peer relationship problems & 2.84 & 1.57 & 19 & 3.06 & 1.66 & 18 & 2.76 & 1.89 & 17 & 2.50 & 1.76 & 18 & 0.84 & \\
\hline Prosocial behavior & 4.95 & 1.99 & 20 & 5.00 & 2.09 & 18 & 4.76 & 2.11 & 17 & 5.44 & 1.92 & 18 & 0.14 & \\
\hline Self-Efficacy & 38.90 & 6.97 & 20 & 42.33 & 8.83 & 18 & 37.50 & 7.54 & 16 & 40.67 & 8.88 & 18 & 3.23 & \\
\hline $\begin{array}{l}\text { Sensitivity of failure } \\
\text { experience }\end{array}$ & 17.10 & 4.61 & 20 & 19.56 & 6.35 & 18 & 16.65 & 5.05 & 17 & 18.83 & 6.91 & 18 & 2.64 & \\
\hline Positive attitude & 21.80 & 4.37 & 20 & 22.78 & 4.56 & 18 & 20.50 & 4.40 & 16 & 21.83 & 4.37 & 18 & 1.86 & \\
\hline Anxiety & 17.65 & 2.78 & 20 & 11.72 & 4.88 & 18 & 11.88 & 4.27 & 17 & 12.44 & 6.33 & 18 & 11.59 & $\star * \star$ \\
\hline Depression & 8.21 & 3.10 & 19 & 7.24 & 2.93 & 17 & 7.13 & 3.10 & 16 & 6.13 & 3.28 & 16 & 2.64 & \\
\hline Anger & 3.70 & 4.91 & 20 & 4.17 & 4.69 & 18 & 4.29 & 4.21 & 17 & 5.65 & 6.63 & 17 & 2.17 & \\
\hline
\end{tabular}


Table 4

Effect sizes compared to pre-intervention assessments for students with high anxiety symptoms $(\mathrm{N}=\mathbf{2 0})$

\begin{tabular}{|c|c|c|c|c|c|c|c|c|c|c|c|c|c|c|c|c|c|}
\hline & \multicolumn{4}{|c|}{ Post-assessment } & \multicolumn{4}{|c|}{ 2-month FU } & & & & \multicolumn{6}{|c|}{ 6-month FU } \\
\hline & $g$ & $95 \% \mathrm{Cl}$ & & & & $g$ & & $95 \% \mathrm{Cl}$ & & & & $g$ & & $95 \% \mathrm{Cl}$ & & & \\
\hline SDQ (Total difficulties) & -0.35 & {$\left[\begin{array}{ll}{[} & -1.02\end{array}\right.$} & , & 0.31 & ] & -0.16 & [ & -0.82 & , & 0.51 & ] & -0.61 & {[} & -1.28 & , & 0.06 & ] \\
\hline Emotional symptoms & -0.31 & {$\left[\begin{array}{ll}-0.95 \\
\end{array}\right.$} & , & 0.33 & ] & -0.05 & {[} & -0.69 & , & 0.60 & ] & -0.49 & {[} & -1.14 & , & 0.15 & ] \\
\hline Conduct problems & -0.10 & {$\left[\begin{array}{ll}-0.75 \\
\quad\end{array}\right.$} & , & 0.56 & ] & -0.13 & {[} & -0.79 & , & 0.52 & ] & -0.50 & {[} & -1.16 & , & 0.15 & ] \\
\hline Hyperactivity/inattention & -0.37 & {$\left[\begin{array}{ll}{[} & -1.01\end{array}\right.$} & , & 0.27 & ] & -0.08 & {[} & -0.73 & , & 0.56 & ] & -0.23 & [ & -0.87 & , & 0.41 & ] \\
\hline $\begin{array}{l}\text { Peer relationship } \\
\text { problems }\end{array}$ & 0.13 & {$\left[\begin{array}{ll}-0.52 \\
\end{array}\right.$} & , & 0.77 & ] & -0.04 & {[} & -0.70 & , & 0.61 & ] & -0.20 & {[} & -0.85 & ' & 0.45 & ] \\
\hline Prosocial behavior & 0.02 & {$\left[\begin{array}{ll}{[} & -0.61\end{array}\right.$} & , & 0.66 & ] & -0.09 & {[} & -0.74 & , & 0.56 & ] & 0.25 & {[} & -0.39 & ' & 0.89 & ] \\
\hline Self-Efficacy & 0.43 & {$\left[\begin{array}{ll}{[} & -0.22\end{array}\right.$} & , & 1.07 & ] & -0.19 & {[} & -0.85 & , & 0.47 & ] & 0.22 & L & -0.42 & ' & 0.86 & ] \\
\hline $\begin{array}{l}\text { Sensitivity of failure } \\
\text { experience }\end{array}$ & 0.44 & {$\left[\begin{array}{ll}{[} & -0.21\end{array}\right.$} & , & 1.08 & ] & -0.09 & {[} & -0.74 & , & 0.55 & ] & 0.29 & {[} & -0.35 & , & 0.93 & ] \\
\hline Positive attitude & 0.21 & {$\left[\begin{array}{ll}{[} & -0.42\end{array}\right.$} & , & 0.85 & ] & -0.29 & {[} & -0.95 & , & 0.37 & ] & 0.01 & {[} & -0.63 & , & 0.64 & ] \\
\hline Anxiety & -1.48 & {$\left[\begin{array}{ll}{[} & -2.20\end{array}\right.$} & , & -0.76 & ] & -1.59 & [ & -2.34 & , & -0.85 & ] & -1.06 & [ & -1.74 & ' & -0.38 & ] \\
\hline Depression & -0.32 & {$\left[\begin{array}{ll}{[} & -0.97\end{array}\right.$} & ' & 0.34 & ] & -0.34 & [ & -1.01 & , & 0.33 & ] & -0.64 & {[} & -1.32 & ' & 0.04 & ] \\
\hline Anger & 0.09 & {$\left[\begin{array}{ll}{[} & -0.54\end{array}\right.$} & , & 0.73 & ] & 0.13 & [ & -0.52 & , & 0.77 & ] & 0.33 & {[} & -0.32 & , & 0.98 & ] \\
\hline
\end{tabular}

\section{Discussion}

This study's aim was to examine the follow-up effectiveness of the Up2-D2 for mental health problems among junior high school students returning to school following the COVID-19-related nationwide school closure in Japan. The results indicate that the Up2-D2 effectively improved anxiety at all measurement time points (post-assessment, two-month follow-up, and six-month follow-up). The effects were relatively small for the whole sample but greater for those with higher anxiety. Therefore, the Up2-D2 could be an effective intervention, especially for anxiety.

Pandemic-related school closures exacerbated both internalizing and externalizing problems in children and adolescents worldwide (Chaabane, Doraiswamy, Chaabna, Mamtani, \& Cheema, 2021; Panda et al., 2021). Furthermore, research indicates that school closures might especially increase anxiety compared to other mental health problems for children and adolescents in Japan (Kishida, Tsuda, et al., 2021). In this study, we implemented the Up2-D2 when children returned to school following nationwide closures in Japan. We found that while anxiety for the whole sample decreased and was maintained for at least six months, no significant improvement was observed for other mental health problems, such as depression and anger. Kishida et al.'s (2021) analysis of feasibility studies using the Up2-D2 for whole students in elementary schools also indicated no significant improvements in depression and anger. These results could be attributed to floor effects such that no improvements were observed.

Moreover, the mean score of 8.31 for anxiety in this study was higher than the score of 5.51 reported in the developmental study for the Japanese short version of the Short CAS (Ishikawa et al., 2018). Additionally, the scores for depression (5.00) and anger (2.19) in this study were equal to or lower than those in previous studies conducted in Japan prior to the pandemic (4.73 for depression, Ishikawa et al., 2018; 4.69 for anger, Takebe et al., 2017). Thus, the Up2-D2 can be more effective for students with higher levels of some mental health problems, such as anxiety, in a society where COVID-19 prevails.

Furthermore, students with higher anxiety showed improvements in both internalizing and externalizing problems. Another transdiagnostic universal prevention program based on cognitive-behavioral interventions was effective for children with greater baseline emotional symptoms (García-Escalera, Valiente, Sandín, Ehrenreich-May, Prieto, \& Chorot, 2020). Previous trials for target-type transdiagnostic prevention programs (i.e., selective and indicated prevention programs) consistently showed significant improvements in both internalizing and externalizing problems in children and adolescents with emotional problems such as anxiety and depression. (Essau, Olaya, Sasagawa, Pithia, Bray, \& Ollendick, 2014; Essau, Sasagawa, Jones, Fernandes, \& Ollendick, 2019; Martinsen et al., 2019; Loevaas et al., 2020). Therefore, target-type transdiagnostic universal prevention programs for students at risk of emotional problems or who have higher symptoms might ameliorate their emotional symptoms more effectively. 
We implemented a school-based transdiagnostic universal prevention program after nationwide school closures were implemented in Japan. Regarding the COVID-19 pandemic, the Up2-D2 had two main strengths. First, it is a universal prevention program applicable for all children and adolescents. During the pandemic and school closures, most children and adolescents have been exposed to the risk of deteriorating mental health problems, especially anxiety. However, a systematic review (Samji et al., 2021) reported that several researchers have noted a decrease in the utilization of mental health services during the COVID-19 pandemic. Therefore, a universal preventive intervention for schools can significantly improve access to mental health support for children and adolescents. Second, this program has a transdiagnostic perspective on internalizing and externalizing problems, both of which have been affected during lockdowns and pandemic-related school closures (Kishida, Tsuda, et al., 2021; Panda et al., 2021). Although previous transdiagnostic prevention programs have primarily focused on internalizing problems such as anxiety and depression (Essau et al., 2014; Essau et al., 2019; Martinsen et al., 2019; Loevaas et al., 2020), the Up2-D2 can be applied to both internalizing and externalizing problems, and its effectiveness has been confirmed, especially in children who show higher anxiety symptoms.

However, this study had several limitations. First, we did not measure fear of the pandemic or school closure; thus, their association with the anxiety measured in this study is unclear. The use of a scale specific to COVID-19-related anxiety should be considered. Second, we did not include a control group in this study due to a practical limitation (i.e., immediately after nationwide school closure), and the possibility of spontaneous recovery of symptoms could not be denied. Third, only self-reported questionnaires were used. A wide range of indicators, such as diagnostic interviews, parent ratings, teacher ratings, and behavioral indicators, is needed in future studies. Fourth, we did not receive information on the extent to which teachers guided children based on the handouts we provided. In the future, it is necessary to measure the procedures implemented during follow-up using countable indicators.

Despite the limitations, this is the first study to demonstrate the effectiveness of a school-based transdiagnostic universal prevention intervention for mental health problems immediately after the nationwide school closure in Japan. This study found that the program was effective for anxiety, and its effects were maintained at follow-up. The pandemic has negatively affected various mental health problems in many children and adolescents worldwide. Thus, the implementation of a transdiagnostic universal prevention program in schools should be considered as an avenue to support children, adolescents, and teachers during the COVID-19 era.

\section{Declarations}

\section{Acknowledgments}

The authors would like to thank students and teachers who participated to the project.

\section{Funding}

This study was funded by The Research Institute of Science and Technology for Society of the Japan Science and Technology Agency (JPMJRX17A1, JPMJRX20IA).

\section{Competing interests}

The authors have no competing or potential conflicts of interest to declare.

\section{Ethics approval}

The study was conducted with the approval of the Institutional Review Board of Doshisha University (approval no. 201904), in accordance with the 1964 Helsinki Declaration or comparable standards.

\section{Consent to participate}

Written informed consent was obtained from school principals. In addition, oral informed consent was obtained from all the students.

\section{Data availability}

The data that support the findings of this study are available on request from the corresponding author.

\section{Author contributions}

All authors contributed to the manuscript. K.K. wrote the first draft of the manuscript. N.H. collected data and co-wrote the manuscript. K.M. and M.O. contributed to the revision of the manuscript. S.I. was a supervisor and a principal investigator of this project.

\section{References}

1. Berger, E., Jamshidi, N., Reupert, A., Jobson, L., \& Miko, A. (2021). The mental health implications for children and adolescents impacted by infectious outbreaks-a systematic review. Child and Adolescent Mental Health, 26(2), 157-166. https://doi.org/10.1111/camh.12453 
2. Birleson, P. (1981). The validity of depressive disorder in childhood and the development of a self-rating scale: A research report. Journal of Child Psychology and Psychiatry, and Allied Disciplines, 22(1), 73-88. https://doi.org/10.1111/j.1469-7610.1981.tb00533.x

3. Chaabane, S., Doraiswamy, S., Chaabna, K., Mamtani, R., \& Cheema, S. (2021). The impact of COVID-19 school closure on child and adolescent health: A rapid systematic review. Children, 8(5), 415. https://doi.org/10.3390/children8050415

4. Denda, K., Kako, Y., Kitagawa, N., \& Koyama, T. (2006). Assessment of depressive symptoms in Japanese school children and adolescents using the Birleson Depression Self-Rating Scale. International Journal of Psychiatry in Medicine, 36(2), 231-241. https://doi.org/10.2190/3YCX-H0MT49DK-C61Q

5. Dray, J., Bowman, J., Campbell, E., Freund, M., Wolfenden, L., Hodder, R. K.,...Wiggers, J. (2017). Systematic review of universal resilience-focused interventions targeting child and adolescent mental health in the school setting. Journal of the American Academy of Child and Adolescent Psychiatry, 56(10), 813-824. https://doi.org/10.1016/j.jaac.2017.07.780

6. Essau, C. A., Olaya, B., Sasagawa, S., Pithia, J., Bray, D., \& Ollendick, T. H. (2014). Integrating video-feedback and cognitive preparation, social skills training and behavioural activation in a cognitive behavioural therapy in the treatment of childhood anxiety. Journal of Affective Disorders, 167 , 261-267. https://doi.org/10.1016/j.jad.2014.05.056

7. Essau, C. A., Sasagawa, S., Jones, G., Fernandes, B., \& Ollendick, T. H. (2019). Evaluating the real-world effectiveness of a cognitive behavior therapy-based transdiagnostic program for emotional problems in children in a regular school setting. Journal of Affective Disorders, 253, 357365. https://doi.org/10.1016/j.jad.2019.04.036

8. Fukui, I., lijima, M., Oyama, M., Nakayama, H., Komatsu, C., Oda, M.,...Sakano, Y. (2009). The general self-efficacy scale for children-revised: Manual Tokyo: Kokoro-Net

9. García-Escalera, J., Valiente, R. M., Sandín, B., Ehrenreich-May, J., Prieto, A., \& Chorot, P. (2020). The unified protocol for transdiagnostic treatment of emotional disorders in adolescents (UP-A) adapted as a school-based anxiety and depression prevention program: An initial cluster randomized wait-list-controlled trial. Behavior Therapy, 51(3), 461-473. https://doi.org/10.1016/j.beth.2019.08.003

10. Goodman, R. (2001). Psychometric properties of the strengths and difficulties questionnaire. Journal of the American Academy of Child and Adolescent Psychiatry, 4O(11), 1337-1345. https://doi.org/10.1097/00004583-200111000-00015

11. Hendriks, A. M., Bartels, M., Colins, O. F., \& Finkenauer, C. (2018). Childhood aggression: A synthesis of reviews and meta-analyses to reveal patterns and opportunities for prevention and intervention strategies. Neuroscience and Biobehavioral Reviews, 91, $278-291$. https://doi.org/10.1016/j.neubiorev.2018.03.021

12. Hida, N., Ishikawa, S., Murasawa, T., \& Oguni, M. (2020). Effect of universal unified prevention program for diverse disorders for junior high school students. Doshisha Clinical Psychology: Therapy and Research, 10,3-13. https://doi.org/10.14988/00027868

13. Horowitz, J. L., \& Garber, J. (2006). The prevention of depressive symptoms in children and adolescents: A meta-analytic review. Journal of Consulting and Clinical Psychology, 74(3), 401-415. https://doi.org/10.1037/0022-006X.74.3.401

14. Ishikawa, S. I., Kishida, K., Oka, T., Saito, A., Shimotsu, S., Watanabe, N.,...Kamio, Y. (2019). Developing the universal unified prevention program for diverse disorders for school-aged children. Child and Adolescent Psychiatry and Mental Health, 13, 44. https://doi.org/10.1186/s13034-019-0303-2

15. Ishikawa, S., Ishii, R., Fukuzumi, N., Murayama, K., Ohtani, K., Sakaki, M.,...Tanaka, A. (2018). Development, reliability, and validity of the Japanese short version of the Spence Children's Anxiety Scale for Adolescents. Anxiety Disorder Research, 10(1), 64-73.

https://doi.org/10.14389/jsad.10.1_64

16. Isumi, A., Doi, S., Yamaoka, Y., Takahashi, K., \& Fujiwara, T. (2020). Do suicide rates in children and adolescents change during school closure in Japan? The acute effect of the first wave of COVID-19 pandemic on child and adolescent mental health. Child Abuse and Neglect, $110(2), 104680$. https://doi.org/10.1016/j.chiabu.2020.104680

17. Kishida, K., Hida, N., \& Ishikawa, S. (2021). Evaluating the effectiveness of a transdiagnostic universal prevention program for both internalizing and externalizing problems in children: Two feasibility studies. https://doi.org/10.21203/rs.3.rs-1070163/v1

18. Kishida, K., Tsuda, M., Waite, P., Creswell, C., \& Ishikawa, S. I. (2021). Relationships between local school closures due to the COVID-19 and mental health problems of children, adolescents, and parents in Japan. Psychiatry Research, 306, 114276.

https://doi.org/10.1016/j.psychres.2021.114276

19. Loevaas, M. E. S., Lydersen, S., Sund, A. M., Neumer, S. P., Martinsen, K. D., Holen, S.,...Reinfjell, T. (2020). A 12-month follow-up of a transdiagnostic indicated prevention of internalizing symptoms in school-aged children: The results from the EMOTION study. Child and Adolescent Psychiatry and Mental Health, 14, 15. https://doi.org/10.1186/s13034-020-00322-w

20. Martinsen, K. D., Rasmussen, L. M. P., Wentzel-Larsen, T., Holen, S., Sund, A. M., Løvaas, M. E. S.,...Neumer, S.-P. (2019). Prevention of anxiety and depression in school children: Effectiveness of the transdiagnostic EMOTION program. Journal of Consulting and Clinical Psychology, 87(2), 212219. https://doi.org/10.1037/ccp0000360

21. Ministry of Education, Culture, Sports, Science and Technology (MEXT) (2020). Retrieved November 17, 2021, Retrieved from https://www.mext.go.jp/

22. Mrazek, P. J., \& Haggerty, R. J. (Eds.) (1994). Reducing risks for mental disorders: Frontiers for preventive intervention research. National Academy Press 
23. Namikawa, T., Tani, I., Wakita, T., Kumagai, R., Nakane, I., Noguchi, H., \& Tujii, M. (2011). Development of a short-form Birleson depression selfrating scale for children. Clinical Psychiatry, 53, 489-496

24. Noda, W., Ito, H., \& Harada, S. (2013). Examining the reliability and validity of the Japanese version of the Strengths and Difficulties Questionnaire Self Ratings Form Using the entire cohort data in one suburban city in Japan. Japanese Journal of Clinical Psychiatry, 42, 119-127

25. Oka, T., Ishikawa, S. I., Shioiri, T., Maruo, K., Stickley, A., Saito, A.,...Kamio, Y. (2021). Changes in self-efficacy in Japanese school-age children with and without high autistic traits after the universal unified prevention program: A single-group pilot study. Child and Adolescent Psychiatry and Mental Health, 15(1), 42. https://doi.org/10.1186/s13034-021-00398-y

26. Panda, P. K., Gupta, J., Chowdhury, S. R., Kumar, R., Meena, A. K., Madaan, P.,...Gulati, S. (2021). Psychological and behavioral impact of lockdown and quarantine measures for COVID-19 pandemic on children, adolescents and caregivers: A systematic review and meta-analysis. Journal of Tropical Pediatrics, 67(1), 122. https://doi.org/10.1093/tropej/fmaa122

27. Samji, H., Wu, J., Ladak, A., Vossen, C., Stewart, E., Dove, N.,...Snell, G. (2021). Mental health impacts of the COVID-19 pandemic on children and youth-a systematic review. Child and Adolescent Mental Health. https://doi.org/10.1111/camh.12501

28. Sanchez, A. L., Cornacchio, D., Poznanski, B., Golik, A. M., Chou, T., \& Comer, J. S. (2018). The effectiveness of school-based mental health services for elementary-aged children: A meta-analysis. Journal of the American Academy of Child and Adolescent Psychiatry, 57(3), $153-165$. https://doi.org/10.1016/j.jaac.2017.11.022

29. Spence, S. H., Sawyer, M. G., Sheffield, J., Patton, G., Bond, L., Graetz, B., \& Kay, D. (2014). Does the absence of a supportive family environment influence the outcome of a universal intervention for the prevention of depression? International Journal of Environmental Research and Public Health, 11(5), 5113-5132. https://doi.org/10.3390/ijerph110505113

30. Takahashi, F., \& Honda, H. (2021). Prevalence of clinical-level emotional/behavioral problems in schoolchildren during the coronavirus disease 2019 pandemic in Japan: A prospective cohort study. JCPP Advances, 1(1), e12007. https://doi.org/10.1111/jcv2.12007

31. Takebe, M., Kishida, K., Sato, M., Takahashi, F., \& Sato, H. (2017). Development of an anger scale for children and adolescents and examination of its reliability and validity. Japanese Journal of Behavior Therapy, 43, 169-179. https://doi.org/10.24468/jjbt.16-180

32. United Nations Educational, Scientific and Cultural Organization (UNESCO). Global monitoring of school closures caused by COVID-19. Retrieved November 17, 2021, Retrieved from https://en.unesco.org/covid19/educationresponse\#schoolclosures

33. Werner-Seidler, A., Perry, Y., Calear, A. L., Newby, J. M., \& Christensen, H. (2017). School-based depression and anxiety prevention programs for young people: A systematic review and meta-analysis. Clinical Psychology Review, 51, 30-47. https://doi.org/10.1016/j.cpr.2016.10.005 